\title{
Structure-Property Relationships of Silicone Biofouling-Release Coatings: Effect of Silicone Network Architecture on Pseudobarnacle Attachment Strengths
}

\author{
JUDITH STEIN ${ }^{1, *}$, KATHRYN TRUBY $^{1}$, CHRISTINA DARKANGELO WOOD ${ }^{1}$, MICHAEL TAKEMORI $^{1}$, \\ MICHAEL VALLANCE ${ }^{1}$, GEOFFREY SWAIN ${ }^{2}$, CHRISTOPHER KAVANAGH $^{2}$, BRETT KOVACH $^{2}$, \\ MICHAEL SCHULTZ ${ }^{2}$, DEBORAH WIEBE ${ }^{3}$, ERIC HOLM ${ }^{4}$, JEAN MONTEMARANO ${ }^{4}$, DEAN WENDT $^{5}$, CELIA SMITH $^{5}$ \\ and ANNE MEYER 6 \\ ${ }^{1}$ GE Global Research Center, One Research Circle, Niskayuna, NY 12309 USA; ${ }^{2}$ Florida Institute of Technology, Melbourne, FL 32901, USA; ${ }^{3}$ Bridger \\ Scientific, Bourne, MA 02532, USA; ${ }^{4}$ NSWCCD, Bethesda, MD 20084, USA; ${ }^{5}$ University of Hawaii, Honolulu, HI 96812, USA; ${ }^{6}$ University of \\ Buffalo, NY 14212, USA
}

Model silicone foul-release coatings with controlled molecular architecture were evaluated to determine the effect of compositional variables such as filler loading and crosslink density on pseudobarnacle attachment strength. Pseudobarnacle adhesion values correlated with filler loadings in both condensation and hydrosilylation-cured silicones. Variation of crosslink density of hydrosilylationcured silicones had an insignificant effect on attachment strength. X-ray photoelectron spectroscopy (XPS) indicated that the mode of failure upon detachment of the pseudobarnacle was dependent upon the crosslink density; samples with high crosslink density failed cohesively within the silicone.

Keywords: silicone foul-release coatings; pseudobarnacle adhesion; condensation cure; hydrosilylation cure

\section{INTRODUCTION}

Biofouling is ubiquitous in the marine environment and compromises the performance of seafaring vessels by decreasing the maximum attainable speed and increasing fuel consumption (Haslbeck \& Bohlander, 1997). Application of an antifouling coating to the exposed surfaces of vessels is the most common method to combat fouling (Bleile \& Rodgers, 1989). Current coatings comprise heavy metals such as tin or copper and may also contain an organic biocide booster. These coatings function by deterring organismal settlement. The use of tin will be banned in 2008, and copper usage is regulated in some European countries (Walker, 1998). Silicone foul-release coatings are currently under evaluation as an alternative nontoxic technology (Callow \& Fletcher, 1994; Brady, 2000; Darkangelo Wood et al., 2000; Truby et al., 2000). Although organisms can attach to silicones, they can be removed either by brushing or by hydrodynamic self-cleaning (Callow et al., 1988; Meyer et al., 1994; Swain \& Schultz, 1996). Fouling coverage on silicone coatings is generally less than on other nontoxic surfaces (Swain et al., 1997; Watermann et al., 1997).

The superior properties of silicones have been attributed to their being within an optimum range of critical surface tension (Goupil et al., 1973; Meyer et al., 1995). It has been suggested that the low glass transition temperature $\left(\mathrm{T}_{\mathrm{g}}\right)$ of silicones as reflected in their molecular mobility may also contribute to their superior fouling-release characteristics (Bausch \& Tonge, 1996; Brady, 1997). The modulus of silicones (and by implication, their rheological properties) may also contribute to their efficacy as fouling release surfaces (Kohl \& Singer, 1999; Brady \& Singer, 2000). Interfacial slippage and friction also play a role in enhancement of release properties of silicones compared with other nonstick surfaces such as fluoropolymers (Newby et al., 1995; Newby \& Chaudhury, 1997).

There are many reports on the utility of silicones as foul-release coatings; however, there are few reports 
of the effect of compositional variables of the coating on bioadhesion strength. Truby et al. (2000) showed that oil incorporation may prove beneficial in decreasing the adhesion of barnacles and certain species of oysters. Bacterial settlement patterns on silicone coatings amended with oils of various compositions were dependent upon the hydrophilicity of the oil that was incorporated into a silicone matrix (Dalton et al., 2000). Wynne et al. (2000) compared the fouling-release performance of a filled condensation-cured RTV (RTV11) with that of an unfilled hydrosilylation system. The attachment strength of barnacles (Balanus eburneus) was lower on the unfilled hydrosilylation cured coating than the filled condensation cured system (RTV11). However, in a separate study Swain et al. (1998) compared the fouling release properties of RTV11 with silica filled system (DC3140) and found that the calcium carbonate filled system outperformed the silica filled system. Wynne et al. (2000) suggested that the better performance of the calcium carbonate filled coating relative to the silica coating could be attributed to a reduction in the surface modulus of the calcium carbonate filled coating resulting from depletion of the calcium carbonate at the surface upon water exposure. Wynne et al. (2000) concluded that a systematic determination of structure property relationships was necessary to fully understand the foul release performance of the coatings.

In order to address the above issues, model systems have been employed in which the molecular architecture of both condensation-cured and hydrosilylation-cured silicone coatings have been controlled and the relationship between coating composition (crosslink density and filler loading) and pseudobarnacle attachment strengths examined.

\section{MATERIALS AND METHODS}

\section{Materials and Panel Preparation}

Silicone polymers, Karstedt's catalyst, dibutyltinbis (acetylacetonate), fumed silica, tetraethylorthosilicate, calcium carbonate, and SS4155 were obtained from GE Silicones. Aluminum panels were obtained from the Q Panel Company.

Model silicone foul release coatings were prepared as in the following examples. A condensation- curable coating with $0 \%$ filler was prepared by combining $100 \mathrm{~g}$ of dimethoxymethylsiloxy terminated polydimethylsiloxane $(\mathrm{MW}=3100$, 0.032 moles) with $3.56 \mathrm{~g}$ tetraethylorthosilicate (0.017 moles) and $0.65 \mathrm{~g}$ dibutyltin bis (acetylacetonate)(1.5 mmoles). As an example of a filled system, a coating with $13 \%$ filler was prepared by combining $87 \mathrm{~g}$ of dimethoxymethylsiloxy terminated polymer ( 0.028 moles), $13 \mathrm{~g}$ calcium carbonate $(0.129$ moles $)$, $3.0 \mathrm{~g}$ tetraethylorthosilicate $(0.014$ moles $)$ and $0.65 \mathrm{~g}$ dibutyltinbis(acetylacetonate) $(1.5 \mathrm{mmoles})$. Samples were dispensed onto aluminum panels primed with SS4155 using a doctor blade. Samples were allowed to cure for $7 \mathrm{~d}$ under ambient conditions prior to testing.

A masterbatch for hydrosilylation-curable model systems was prepared by combining $200 \mathrm{~g}$ of hexamethydisilazane treated fumed silica and $800 \mathrm{~g}$ of vinylterminated polydimethylsiloxane (equivalent weight $=4111$ ). The masterbatch was combined with additional vinyl polymer if necessary, mixtures of crosslinkable hydride polymer (equivalent weight $=102$ ) and linear hydride (equivalent weight $=1257$ ) so that the ratio of total hydride to vinyl was maintained at 1.2/1.0. To the mixture was added $10 \mathrm{mg}$ of tetravinyltetramethylcyclotetrasiloxane $(0.000023$ moles $)$ followed by $10 \mu \mathrm{l}$ of Karstedt's catalyst $(10.9 \% \mathrm{Pt}, 4.8 \mu \mathrm{mol}$ $\mathrm{Pt})$. The amounts of masterbatch, linear vinyl, linear hydride, and crosslinkable hydride polymers for the different coating systems are given in Table I.

Aluminum panels were coated using the procedure described above for the condensation-curable systems.

\section{Laboratory Testing}

The tensile properties of the model foul-release coatings were obtained in accordance with ASTM Method D412, using 1-1.5 mm thick sheets of the cured coating. Contact angle measurements were performed according to literature methods using a Rame-Hart NRL100 goniometer. Critical surface tensions were calculated using Zisman plots (Baier \& Meyer, 1992; Meyer et al., 1994; 1997). Surface roughness was determined using a Park Universal Scanning Probe operating in the contact mode at a $1 \mathrm{~Hz}$ line scan rate. The rheological properties

TABLE I Composition of hydrosilylation cured model systems

\begin{tabular}{lcccc}
\hline Coating type & Masterbatch $(\mathrm{g})$ & Vinyl polymer $(\mathrm{g})$ & Linear hydride $(\mathrm{g})$ & Crosslinking hydride $(\mathrm{g})$ \\
\hline $16 \%$ filler 50/50 hydride ratio & 80 & 5.0 & 13.5 & 7.28 \\
$16 \%$ filler 25/75 hydride ratio & 80 & 10.6 & 1.1 \\
$16 \%$ filler 0/100 hydride ratio & 80 & 17.4 & 14.5 & 1.78 \\
$10 \%$ filler 50/50 hydride ratio & 50 & 34 & 15.3 & 1.12 \\
$5 \%$ filler 50/50 hydride ratio & 25 & 58 & 1.24 \\
\hline
\end{tabular}




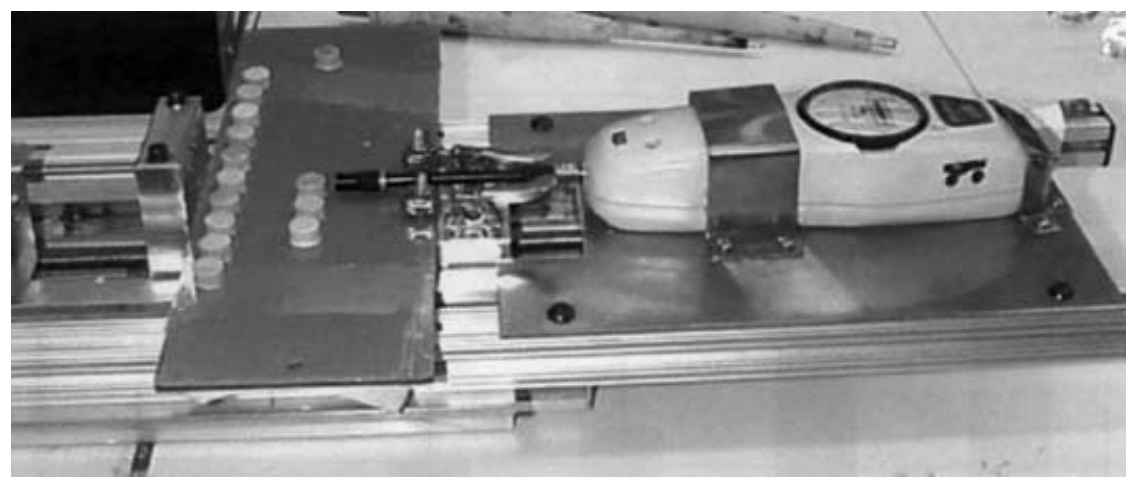

FIGURE 1 Pseudobarnacle adhesion tester.

were obtained on a Rheometrics System IV spectrometer over a frequency range of $1 \times 10^{-1}$ to $1 \times 10^{2} \mathrm{rad} \mathrm{s}^{-1}$.

\section{Pseudobarnacle Adhesion Tests}

Pseudobarnacle adhesion measurements were performed on calcium carbonate filled coatings using ASTM D5618 (Swain et al., 1997). For hydrosilylation cured samples, the tests were modified as follows. Wooden studs of known diameter were glued to the silicone surface using Epoxi-Patch obtained from the Dexter Corporation. The adhesive was allowed to harden for $5 \mathrm{~d}$ under ambient conditions before testing. In this case, the force gauge was mounted on a traveling rack that moved at $0.63 \mathrm{~cm} \mathrm{~s}^{-1}$ or $0.08 \mathrm{~cm} \mathrm{~s}^{-1}$ parallel to the coating surface (see Figure 1). From an analysis of variance (ANOVA), the velocity of the traveling rack had no effect on pseudobarnacle adhesion values (probability value $(P)=0.174$, degrees of freedom $(\mathrm{df})=59)$.

\section{$X$-ray Photoelectron Spectroscopy (XPS)}

The XPS measurements were conducted in a Surface Science Instruments SSX-100 system, employing a monochromatic Al k $\alpha$ source $(600 \mu$ spot). A fixed pass energy of $150 \mathrm{eV}$ was used for survey scans, and $50 \mathrm{eV}$ for high resolution scans of individual core levels. The surface charging that occurred due to the nonconductive nature of the samples was neutralized with 1-2 eV low energy electrons from an electron flood gun. Atomic compositions were computed from XPS peaks using empirically determined sensitivity factors derived from measurements on standard materials. The $\mathrm{C} 1 \mathrm{~s}$ signal was curve fitted using mixed Gaussian/Lorentzian line shapes. The binding energy of the $\mathrm{C} 1 \mathrm{~s}$ signal from the hydrocarbon at $284.6 \mathrm{eV}$ was used as an internal calibration of the absolute binding energy scale.

\section{RESULTS AND DISCUSSION}

\section{Condensation Curable Silicone Coatings}

In order to quantify the effect of filler loading on organismal detachment strengths, moisture-curable silicone networks containing $0 \%$ to $29 \%$ calcium carbonate were prepared by the reaction of dimethylmethylsiloxy endcapped-polydimethylsiloxane with tetraethylorthosilicate and the appropriate filler amount using dibutyltinbis(acetylacetonate) as the catalyst. Pseudobarnacle adhesion values were obtained rather than barnacle adhesion values in order to decrease the standard error in measurement as well as to decrease the experimental time and serendipity of barnacle settlement. Swain et al. (1997) showed that over large ranges in organismal adhesion, an excellent correlation existed between pseudobarnacle adhesion strength and barnacle adhesion strength for silicone coatings.

Pseudobarnacle adhesion values were shown to increase as the filler loading increased (see Figure 2, $\mathrm{df}=99, p=0.000$ ). As the filler loading increased, the tensile strength of the coating also increased; thus, the higher the tensile strength of the coating, the greater the pseudobarnacle adhesion (see Figure 3). Note that in order to reduce the pseudobarnacle adhesion strength to $1 / 2$ of the highest value, the tensile strength of the coating must be reduced to $1 / 4$. Therefore, coatings with the greatest durability and strength will be the least effective in terms of easy removal of fouling organisms.

Kendall (1971) reported that the release performance of elastomers depended on both the surface energy and elastic properties. He developed the equation below to relate the reversible pull-off force of a stud bonded to thin elastomeric glue:

$$
\mathrm{P}_{\mathrm{c}}=\pi \mathrm{a}^{2}\left(2 \omega_{\mathrm{a}} \mathrm{K} / \mathrm{t}\right)^{1 / 2}
$$

where $P_{c}, t, \omega_{a}, K$ and a are respectively, the critical pull off force, thickness of the coating, work of adhesion, elastomer bulk modulus, and contact radius. In his experiments, the detachment rate was 


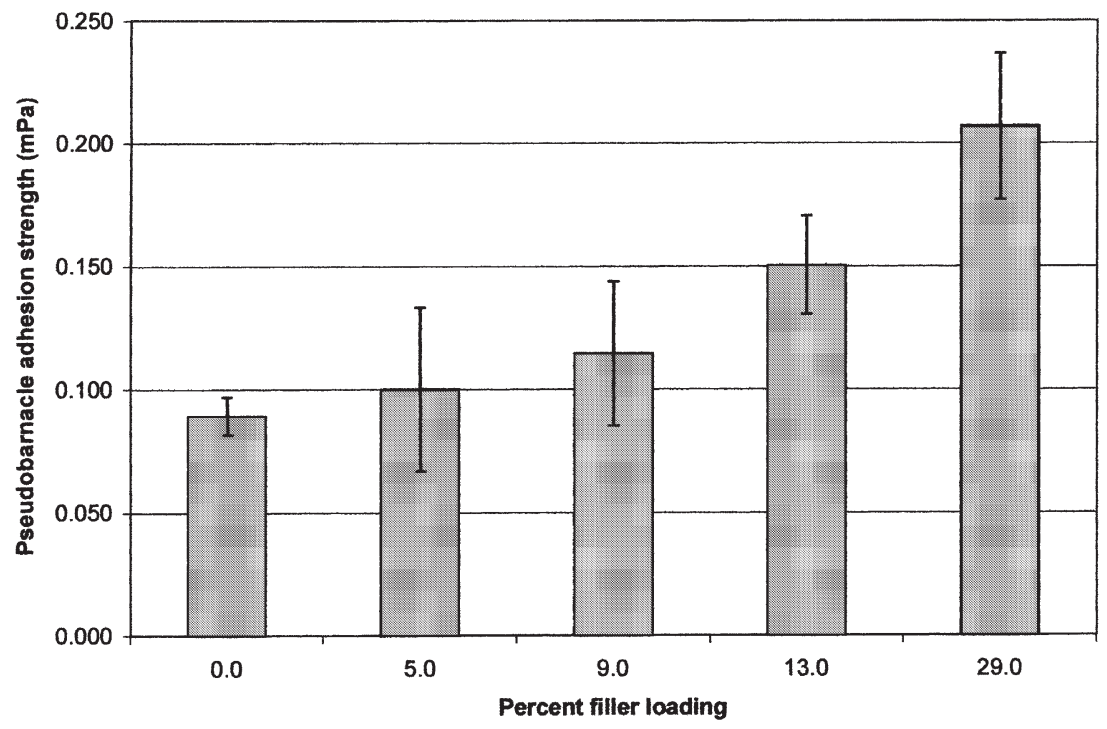

FIGURE 2 Effect of filler loading on pseudobarnacle adhesion strength in condensation-cured systems $(\mathrm{df}=99, p=0.000)$. Error bars $=$ one SD.

essentially zero and therefore, dissipative processes could be ignored. Kohl and Singer (1999) have successfully applied the Kendall equation to silicone duplex coatings, where they demonstrated the thickness dependence of the pull off force.

The present authors have derived an equation to relate the shear pull-off stress with the shear modulus and fracture energy as shown below. In this case, the fracture energy is comprised of reversible (surface energy) and irreversible (dissipative) terms because the tests were not performed at infinitely slow speeds.

$$
\sigma_{\mathrm{f}}=\left(2 \mathrm{G}_{\mathrm{a}} \mathrm{G}^{\prime} / \mathrm{t}\right)^{1 / 2}
$$

where $\sigma_{\mathrm{f}}$ is the critical pull-off stress, $\mathrm{G}_{\mathrm{a}}$ is the fracture energy, $G^{\prime}$ is the shear storage modulus at low frequency and $t$ is the thickness of the coating. This equation is analogous to that obtained from the fracture energy analysis of lap shear joints (Wu, 1982). The applicability of this equation is restricted to cases where the radius of the stud was much greater than the thickness of the coating.

The storage moduli $\left(\mathrm{G}^{\prime}\right)$ were determined independently allowing for the determination of the ratio $G_{a} / t$ at each filler loading. The storage modulus of the coatings increased with increasing filler loadings; since the thicknesses were essentially the same for all coatings and all surfaces have

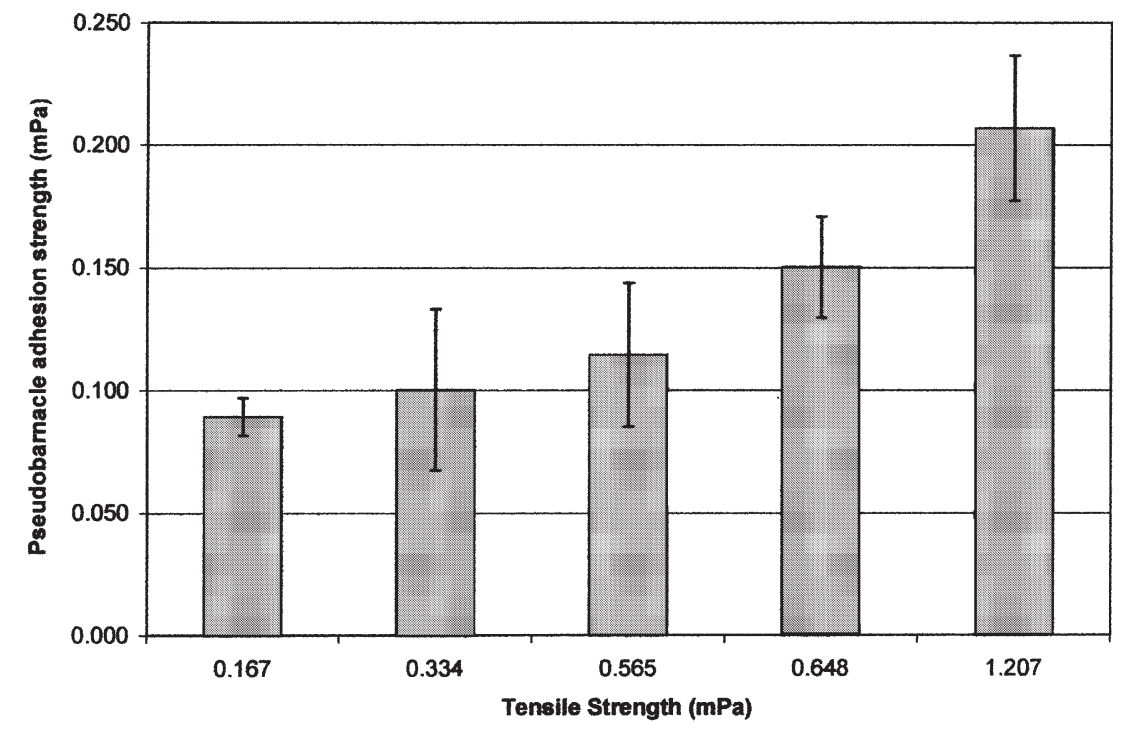

FIGURE 3 Correlation of pseudobarnacle adhesion strength with tensile strength of condensation-cured silicones $(\mathrm{df}=99, p=0.000)$. Error bars = one SD. 
TABLE II Model condensation cured coating properties

\begin{tabular}{lcccc}
\hline Filler loading & $\begin{array}{c}\text { Storage modulus } \\
\left(\mathrm{G}^{\prime} ; \mathrm{mPa}\right)\end{array}$ & Tan $\delta$ & $\begin{array}{c}\text { Psuedobarnacle adhesion strength } \\
\left(\sigma_{\mathrm{f}} ; \mathrm{mPa}\right)\end{array}$ & $\begin{array}{c}\text { Fracture Energy/thickness } \\
(\mathrm{Ga} / \mathrm{t} ; \mathrm{mPa})\end{array}$ \\
\hline $0 \%$ filler & 0.298 & 0.036 & 0.09 & 0.10 \\
$5 \%$ filler & 0.320 & 0.034 & 0.11 & 0.013 \\
$9 \%$ filler & 0.333 & 0.036 & 0.15 & 0.016 \\
$13 \%$ filler & 0.338 & 0.045 & 0.21 & 0.033 \\
$29 \%$ filler & 0.544 & 0.050 & 0.039 \\
\hline
\end{tabular}

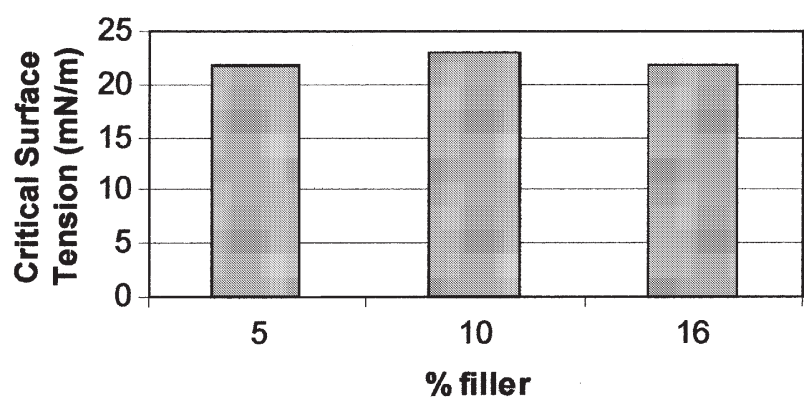

FIGURE 4 Negligible effect of filler loading on critical surface tension of hydrosilylation cured silicone coating.

the same critical surface tension, then any difference in $G_{a}$ among the samples must be due to dissipative processes. As the filler loading increased there was a corresponding increase in fracture energy. As verification of an increase in dissipative processes as the filler loading increased, a strong positive correlation between the $G_{a} / t$ and $\tan \delta$ of the coating was observed $\left(\mathrm{R}_{\text {pearson }}=0.984\right.$, $p=0.002$ ) (Table II). Thus, both the shear modulus of the coating and the dissipative component of the fracture energy increased with increasing filler loading, resulting in higher stresses for pseudobarnacle removal from coatings with higher filler loadings.

\section{Hydrosilylation-Cured Silicone Coatings}

Hydrosilylation-cured silicones have the advantage that both the filler loading and crosslink density can be controlled, allowing for a complete descrip- tion of the molecular architecture. Coatings were prepared according to the scheme below. In this scheme the ratio of crosslinkable poly (dimethyl)(methylhydride)siloxane with multiple hydride groups on the polymer chain and hydride termination was varied between 50/50 and 100/0, while the overall ratio of hydride to vinyl groups was maintained at a ratio of $1.2 / 1$. Filler loadings were also varied from 5 to $16 \%$ for the composition that contained a 50/50 ratio of crosslinkable to linear hydride.

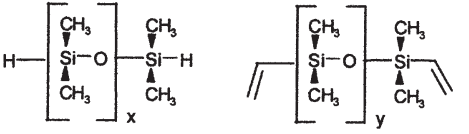

$$
\begin{aligned}
& \text { linear hydride } \\
& \text { linear vinyl }
\end{aligned}
$$

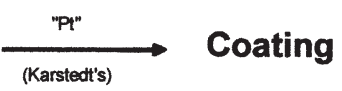

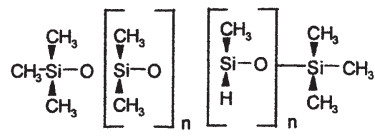

Meyer et al. (1995) suggested that fouling-release ability is related to the critical surface tension of the coating. Critical surface tension measurements were performed to confirm that the surface energy of the coating did not change upon variation of filler loading in hydrosilylation-cured coatings. No change was observed as the filler level was increased from 5 to $16 \%$ (see Figure 4). Surface profiles were

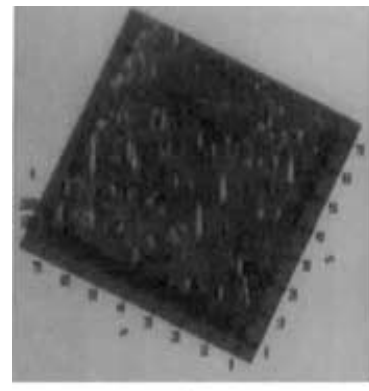

A

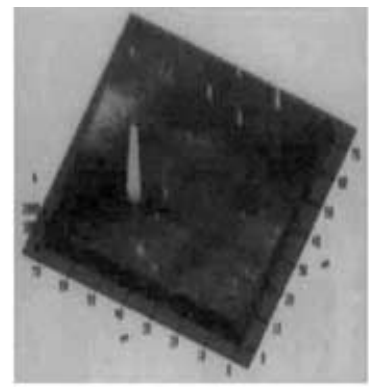

B

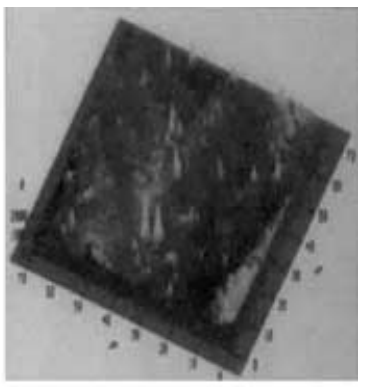

C

FIGURE 5 Effect of filler loading on surface roughness of hydrosilylation cured silicone coatings. A $=5 \%$ filler, rms roughness $=14$ nanometers; $\mathrm{B}=10 \%$ filler, rms roughness $=17$ nanometers; $\mathrm{C}=16 \%$ filler, rms roughness $=19$ nanometers. 


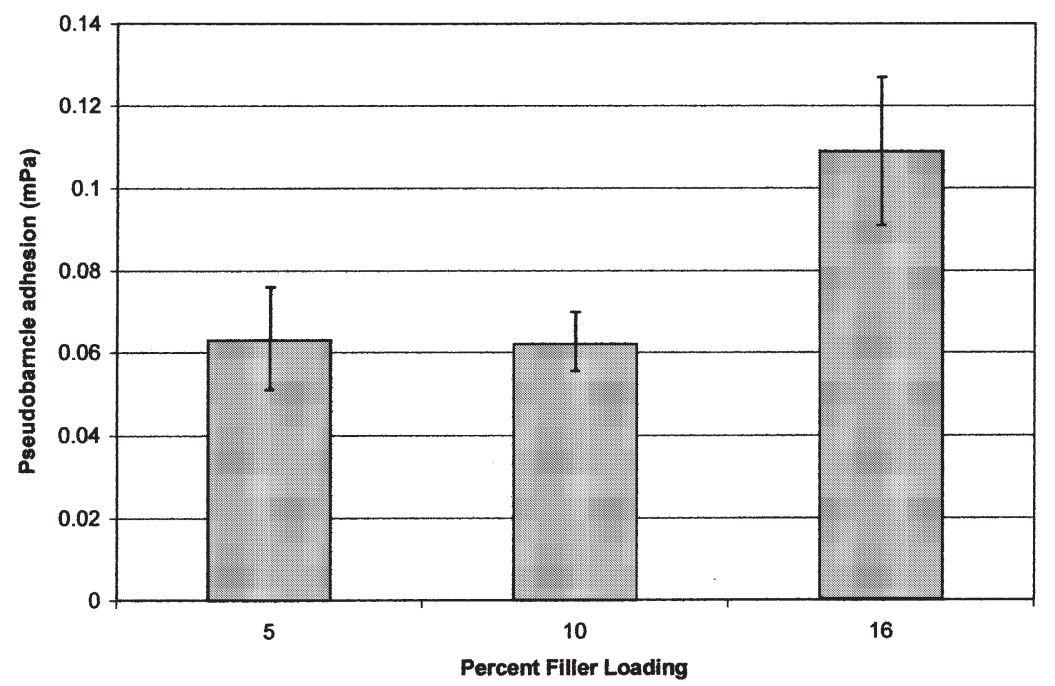

FIGURE 6 Effect of filler loading of hydrosilylation cured silicone coating on pseudobarnacle adhesion $(\mathrm{df}=35, p=0.000)$. Error bars $=$ one SD.

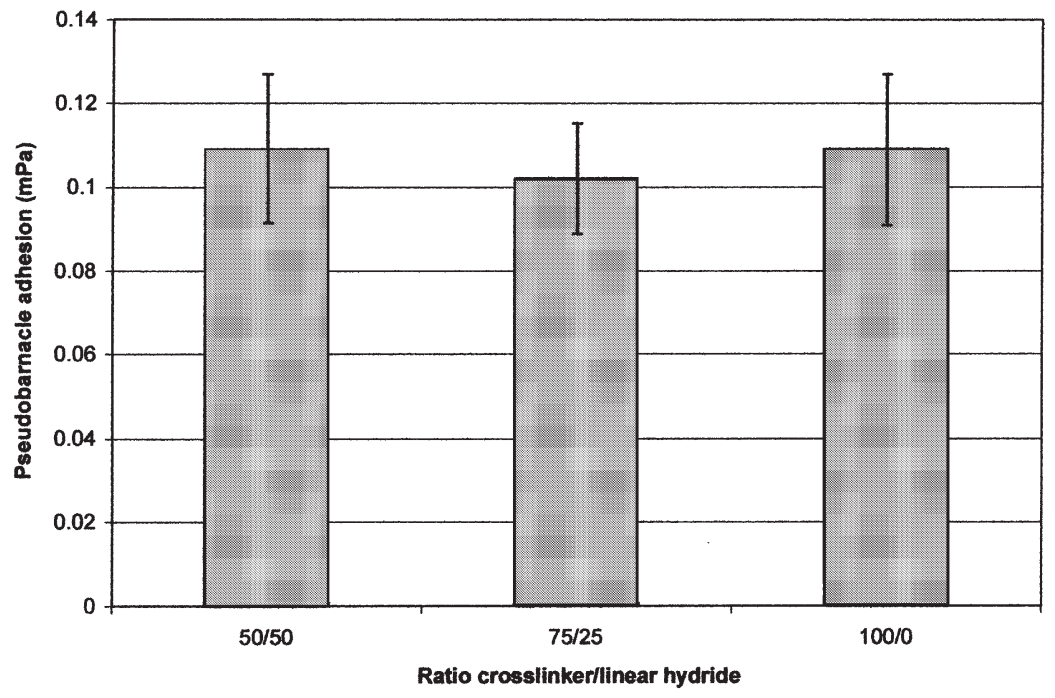

FIGURE 7 Effect of crosslink of hydrosilylation-cured silicone coatings on pseudobarnacle adhesion $(\mathrm{df}=35, p=0.447)$. Error bars $=$ one SD.

also obtained, indicating that filler level had no appreciable effect on surface roughness (see Figure 5).

Variation of the filler loading from 5 to $16 \%$ led to a corresponding increase in the pseudobarnacle

TABLE III Physical properties of model hydrosilylation cured systems

\begin{tabular}{lccl}
\hline $\begin{array}{l}\text { Filler } \\
\text { loading }\end{array}$ & $\begin{array}{c}\text { Crosslinker/linear } \\
\text { hydride ratio }\end{array}$ & $\mathrm{G}^{\prime}(\mathrm{mPa})$ & Tan $\delta$ \\
\hline 5 & $50 / 50$ & 0.306 & 0.005 \\
10 & $50 / 50$ & 0.349 & 0.0100 \\
16 & $50 / 50$ & 0.386 & 0.0200 \\
16 & $75 / 25$ & 0.504 & 0.011 \\
16 & $100 / 0$ & 0.592 & 0.0096 \\
\hline
\end{tabular}

attachment strength (see Figure 6, $\mathrm{df}=35$, $p=0.000)$. This result is consistent with the result obtained on condensation cured silicones. The fact that these surfaces have identical critical surface tensions yet exhibit different release properties again implies that other factors beside surface energy are important in defining performance.

The ratio of crosslinker hydride to linear hydride had no effect on pseudobarnacle adhesion values (Figure 7, $\mathrm{df}=35, p=0.447$ ). However, this may be explained by the inverse relationship between $\tan \delta$ and $\mathrm{G}^{\prime}$ for these coatings (Table III). As the crosslink density is increased, $G^{\prime}$ increases whereas tan $\delta$ decreases. These opposing forces result in negligible differences in pseudobarnacle adhesion strengths as the crosslink density of the coating is varied. 
TABLE IV Effect of silicone architecture of hydrosilylation-cured coatings on the failure mode in pseudobarnacle adhesion tests

\begin{tabular}{lcc}
\hline Filler loading & Crosslinker/linear hydride ratio & Pseudobarnacle adhesion strength (mPa) \\
\hline 5 & $50 / 50$ & $0.063+/-0.013$ \\
10 & $50 / 50$ & $0.062+/-0.008$ \\
16 & $50 / 50$ & $0.109+/-0.018$ \\
16 & $75 / 25$ & $0.102+/-0.013$ \\
16 & $100 / 0$ & $0.109+/-0.017$ \\
\hline
\end{tabular}

Berglin and Gatenholm (1999) reported that small amounts of uncrosslinked silicone from both hydrosilylation-cured and condensation-cured silicones are transferred to the pseudobarnacles upon detachment from the surfaces. The failure mode in the present hydrosilylation-cured systems was examined using XPS (Table II). Transfer of silicone to the pseudobarnacles was small at all filler loadings at a constant crosslinker hydride to linear hydride ratio of 50/50. However, the amount of silicone on the pseudobarnacle increased as the crosslinker hydride to linear hydride ratio increased at constant filler loading. At $100 \%$ crosslinker hydride, the failure mode is certainly cohesive within the silicone since the amount of silicon present on the pseudobarnacle surface is equivalent to the atomic composition of the silicone $(21 \%)$. This implies a change in fracture mechanism as a function of crosslink density. Thus, although the adhesion strength is not dependent on crosslink density of the coating, the fracture mechanism becomes cohesive within the silicone as the coating becomes more brittle (Table IV).

\section{CONCLUSION}

ANOVA analysis of the attachment strength of psuedobarnacles to model silicone coatings have provided data that suggest that coatings with lower filler loadings will have better fouling-release properties than those with higher filler levels. This result is independent of filler type (silica or calcium carbonate). The most durable coatings contain high filler loadings. Crosslink density had an insignificant effect on attachment strengths of pseudobarnacles but changed the failure mechanism, suggesting that lower crosslink densities are preferred for durable coatings. These results suggest a trade-off between mechanical integrity of the coatings and foul release performance. Research is underway to enhance the fouling-release ability of silicone coatings without compromising durability.

\section{Acknowledgements}

Mike Shultz is thanked for obtaining the pseudobarnacle adhesion measurements on the calcium carbonate filled systems. John Chera is thanked for
XPS measurements; Dr Bill Morris is thanked for the AFM experiments. Professor Manoj Chaudhury, Dr Harold Guard and Dr Steven Wax are thanked for helpful discussions. The research was supported by DARPA (contract number N00017-96-C0145).

\section{References}

Baier R E, Meyer A E (1992) Surface analysis of fouling-resistant marine coatings. Biofouling 6: 165-180

Bausch G G, Tonge J S (1996) Silicone technology for foulingrelease coating systems. Proc Waterborne High Solids Powder Coat Symp 23: 340-353

Berglin M, Gatenholm P (1999) The nature of bioadhesive bonding between barnacles and fouling release silicone coatings. J Adhesion Sci Technol 13: 713-727

Bleile H R, Rodgers S (1989) Marine coatings: In: Brezinski D, Mirinda $\mathrm{T}$ (eds) Federation Series on Coatings Technology. Federation of Societies for Coating Technology, Philadelphia, pp 14-28

Brady R F (1997) In search of non-stick coatings. Chem Ind (Lond) 6: 219-222

Brady R F (2000) Clean hulls without poisons: devising and testing nontoxic marine coatings. I Coatings Technol 72: 44-45, 47-56

Brady R F, Singer I (2000) Mechanical factor favoring release from fouling release coatings. Biofouling 15: 73-82

Callow M E, Fletcher R L (1994) The influence of low surface energy materials on bioadhesion - a review. Int Biodeterior Biodegr 133: 333-348

Callow M E, Pitchers R A, Santos R (1988) Non-biocidal antifouling coatings. In: Houghton D R, Smith R N, Eggins $\mathrm{H}$ $\mathrm{O}$ W (eds) Biodeterioration 7. Elsevier Applied Science, Oxford, pp $43-48$

Dalton H, Stein J, March P (2000) A biological assay for detection of heterogeneities in the surface hydrophobicity of polymer coatings exposed to the marine environment. Biofouling 15: 83-94

Darkangelo Wood C, Truby K, Stein J, Wiebe D, Holm E, Wendt D, Smith C, Kavanagh C, Montemarano J, Swain G, Meyer A (2000) Temporal and spatial variations in macrofouling of silicone fouling-release coatings. Biofouling 16: 311-322

Goupil D W, DePalma V A Baier R E (1973) Prospects for nontoxic fouling resistant paints. Proc 9th Ann Conf Marine Technol Soc, pp 445-458

Haslbeck E, Bohlander G (1997) Hydrodynamic drag evaluation of antifouling coatings-laboratory and field. Proc Emerging Nonmetallic Materials for the Marine Environment 1: 45-51

Kendall K (1971) The adhesion and surface energy of elastic solids. J Phys D: Applied Phys 4: 1186-1195

Kohl J G, Singer I L (1999) Pull-off behavior of epoxy bonded to silicone duplex coatings. Prog Organic Coatings 36: 15-20

Meyer A E, Baier R E, Forsberg R L (1994) Field trials of nontoxic fouling release coatings. Proc 4th Int Zebra Mussel Conf, Report No TR-104029. Electric Power Research Institute, Palo Alto, CA, pp 273-290

Meyer A E, Baier R E, Forsberg R L (1995) Degradation of nontoxic fouling-release coatings as a result of abrasion and long-term exposure. Proc 5th Int Zebra Mussel and Other Aquatic Nuisance Organisms Conf, pp 337-342

Meyer A E, Baier R E, Kohl J, Singer I L, Griffith J, Haslbeck E, Montemarano J A, Ross A, Schultz M, Swain G (1997) Duplex 
foul release coating (Environmental Security Technology Certification Program: advanced nontoxic antifouling coatings technology demonstration), NSWCCC-TR-64-95/15

Newby B-M, Chaudhury M K, Brown H R (1995) Macroscopic evidence of the effect of interfacial slippage on adhesion. Science 269: 1407-1409

Newby B-M, Chaudhury M K (1997) Effect of interfacial slippage on viscoelastic adhesion. Langmuir 13: 1805-1809

Swain G W, Schultz M P (1996) The testing and evaluation of nontoxic antifouling coatings. Biofouling 10: 187-197

Swain G W, Schultz M P, Griffith J, Snyder S (1997) The relationship between barnacle and pseudobarnacle adhesion measurements as a method to quantify the foul release properties of silicones. Proc Emerging Nonmetallic Materials for the Marine Environment 1: 60-69

Swain G W, Schultz M, Kavanagh C, Cook A, Haslbeck E G, Meyer A E, Baier R E (1998) The performance of fouling release coatings: static immersion at seven sites worldwide. Report I, Intercalibration study, Report to the Office of Naval Research, July 1998

Truby K, Wood C, Stein J, Cella J, Carpenter J, Kavanagh C, Swain G, Wiebe D, Lapota D, Meyer A, Holm E, Wendt D, Smith C, Montemarano J (2000) Evaluation of the performance enhancement of silicone biofouling - release coating by oil incorporation. Biofouling 15: 141-150

Walker I (1998) Non-toxic fouling control systems. Pitture Vernici Eur 13: 17-22

Watermann B, Berger H-D, Sonnichsen H, Willemsen P (1997) Performance and effectiveness of non-stick coatings in seawater. Biofouling 11: 101-119

Wu S (1982) Polymer Interface and Adhesion. Marcel Dekker, NY

Wynne K J, Swain G W, Fox R B, Bullock S, Ulik J (2000) Two silicone nontoxic fouling release coatings: hydrosilylation cured PDMS and $\mathrm{CaCO}_{3}$ filled ethoxysilane cured RTV11. Biofouling 16: $277-288$ 